\title{
Vitreomacular traction syndrome: New non-surgical treatmeants
}

\section{Tracción vitreomacular: Nuevos tratamientos no-quirúrgicos}

\author{
Paula Maqueda-González ${ }^{1 *}$ and Pablo de Marcelo-Benito ${ }^{2}$
}

${ }^{1}$ Bachelor of Medicine and Surgery from the Universidad Autónoma de Madrid, Ophthalmology Resident; ${ }^{2}$ Bachelor of Medicine and Surgery from the Universidad de Navarra, Physician of the Medical-Surgical Retina Section. Hospital Virgen de la Montaña, Cáceres, España

\begin{abstract}
Introduction: Vitreomacular traction syndrome is described as a maculopathy in which incomplete vitreous detachment associated with macular traction and visual acuity decrease occurs. Clinical case: We present the case of a 54-year-old female with bilateral vitreomacular traction syndrome not coincident in time. In the right eye, it resolved spontaneously after 12 months of follow-up. The left eye was treated by pharmacological vitreolysis with ocriplasmin (JETREA ${ }^{\bullet}$, Alcon Laboratories, Fort Worth, TX, USA), achieving functional and anatomical recovery in 3 months. Discussion: Enzymatic vitreolysis achieves a fundamental early treatment to obtain good results that allow maximum preservation of visual function and retinal anatomy.
\end{abstract}

Key words: Posterior vitreous detachment. Vitreomacular traction syndrome. Vitreo-retinal interface. Macular hole. Vitrectomy. Enzymatic vitreolysis.

\section{Resumen}

Introducción: El síndrome de tracción vitreomacular se describe como la maculopatía en la que se produce un desprendimiento incompleto del vítreo asociado a tracción macular y disminución de la agudeza visual. Caso clínico: Se presenta el caso de una mujer de 54 años con síndrome de tracción vitreomacular bilateral no coincidentes en el tiempo. En el ojo derecho este se resolvió espontáneamente en 12 meses de seguimiento. En el ojo izquierdo se trató mediante vitreolisis farmacológica con ocriplasmina (JETREA ${ }^{\circledR}$, Alcon Laboratories, Fort Worth, TX, EE. UU.), consiguiendo la recuperación funcional y anatómica en 3 meses. Discusión: La vitreolisis enzimática consigue un tratamiento precoz fundamental para obtener unos buenos resultados que permitan preservar al máximo la función visual y la anatomía retiniana.

Palabras clave: Desprendimiento de vítreo posterior. Síndrome de tracción vitreomacular. Interfase vítreo-retina. Agujero macular. Vitrectomía. Vitreolisis enzimática.

\section{Correspondence:}

*Paula Maqueda-González

E-mail: paulamaquedag@gmail.com
Available online: 07-05-2018 Rev Mex Oftalmol (Eng). 2018;92(2):90-93 www.rmo.com.mx 2604-1731/O 2016 Sociedad Mexicana de Oftalmología Published by Permanyer México SA de CV. This is an Open Access article under the CC BY-NC-ND license (http://creativecommons.org/licenses/by-nc-nd/4.0/). 


\section{Introduction}

In 1970, Reese et al. described an unusual maculopathy in which there was an incomplete detachment of the vitreous associated with macular traction and decreased visual acuity 1 .

Currently, vitreomacular traction syndrome (VMT) must combine a vitreomacular adhesion that, instead of resolving spontaneously, causes an anatomical distortion of the macular architecture ${ }^{2}$.

This case is presented in order to detail a novel way to treat this disease in a less invasive way.

\section{Clinical case}

A 54-year-old female, who went to the emergency room due to metamorphopsia in her right eye that initiated 10 days before.

In her previous ophthalmological history, a best-corrected visual acuity (BCVA) of 20/20 was recorded in both eyes.

Ophthalmological examination revealed intraocular pressure of $16 \mathrm{mmHg}$ in both eyes. Under slit-lamp examination, there was slight nuclear sclerosis; the rest of the examination was unremarkable. In the fundus macular drusen were observed in both eyes.

BCVA was 20/30 in the right eye and 20/20 in the left eye. Optical coherence tomography was performed, revealing vitreomacular traction syndrome with cavitation in the right eye and diffuse vitreomacular adhesion in the left eye, without associated retinal disease.

In the right eye, the syndrome resolved spontaneously during 12 months of follow-up. In subsequent monthly examinations, the visual acuity of the right eye improved progressively until reaching a BCVA of 20/20 a year later, in February 2015; at that time the foveal profile was normal by optical coherence tomography (Fig. 1).

A decrease in visual acuity was documented in the left eye, with a BCVA of 20/35; at that point, the patient started showing optical coherence tomography alterations.

Optical coherence tomography showed diffuse macular adhesion. Three months later, tomographic control showed retinal cystic alterations together with a vitreous pattern in "gull wings" configuration without an associated epiretinal membrane.

It was decided to treat with intravitreal ocriplasmin (JETREA $^{\circledR}$, Alcon Laboratories, Fort Worth, TX, USA) with a single injection. One week after the injection, BCVA increased to $20 / 30$ and was normal three months later (BCVA of 20/20). At this moment, the alterations observed by optical coherence tomography were resolved, with a normal foveal profile (Fig. 2).

\section{Discussion}

The vitreous is responsible for the stabilization of the eyeball ${ }^{3}$. It is formed by type II collagen fibers whose spaces are filled with water $(98 \%)$ and hyaluronic acid ${ }^{3}$.

The aging of the vitreous induces progressive liquefaction coupled with weakening of vitreoretinal adhesions until the vitreous separates from the retina, inducing a posterior vitreous detachment ${ }^{4}$.

The incidence appears to be higher in women, greater than $65 \%$, attributed to early vitreous liquefaction associated with a possible decrease in estrogen levels in menopause ${ }^{1}$. It is also more frequent in patients with myopia ${ }^{3}$.

The collagen fibers that form the posterior vitreous cortex are firmly attached to the macula and are connected to the internal limiting membrane by proteoglycans, laminin and fibronectin ${ }^{3,4}$. Other anchoring points are the optic disk and the large retinal vessels ${ }^{1}$.

A portion of the vitreous may remain attached to the surface of the macula when the posterior detachment of the vitreous is incomplete, which is known as vitreomacular adhesion. If traction increases due to anteroposterior or tangential forces, VMT may occur, which can be symptomatic in the form of metamorphopsia, micropsia and loss of central visual acuity ${ }^{1,4}$. Although there are some patients with visible VMT syndrome who are asymptomatic ${ }^{1}$.

VMT can generate cystic spaces in the retina and lead to the formation of a macular hole ${ }^{2,3}$. In addition, in many cases it coexists with an epiretinal membrane and thinning of the macular profile?

Establishing a clinical diagnosis of VMT by studying the fundus is difficult? 2 .

With similar results to biomicroscopic exploration, B-mode ultrasound can be used in cases where opacity of media exists, optical coherence tomography cannot be used or it is not available? .

Optical coherence tomography is presented as a revolutionary modality that allows the evaluation of the vitreomacular interface in a non-invasive way?

Currently there is no consensus on what would be the ideal protocol to follow in all VMT cases.

Some cases resolve spontaneously with good anatomical and functional recovery ${ }^{2}$. However, the resolution time is longer compared to when an active treatment is used ${ }^{4}$. 

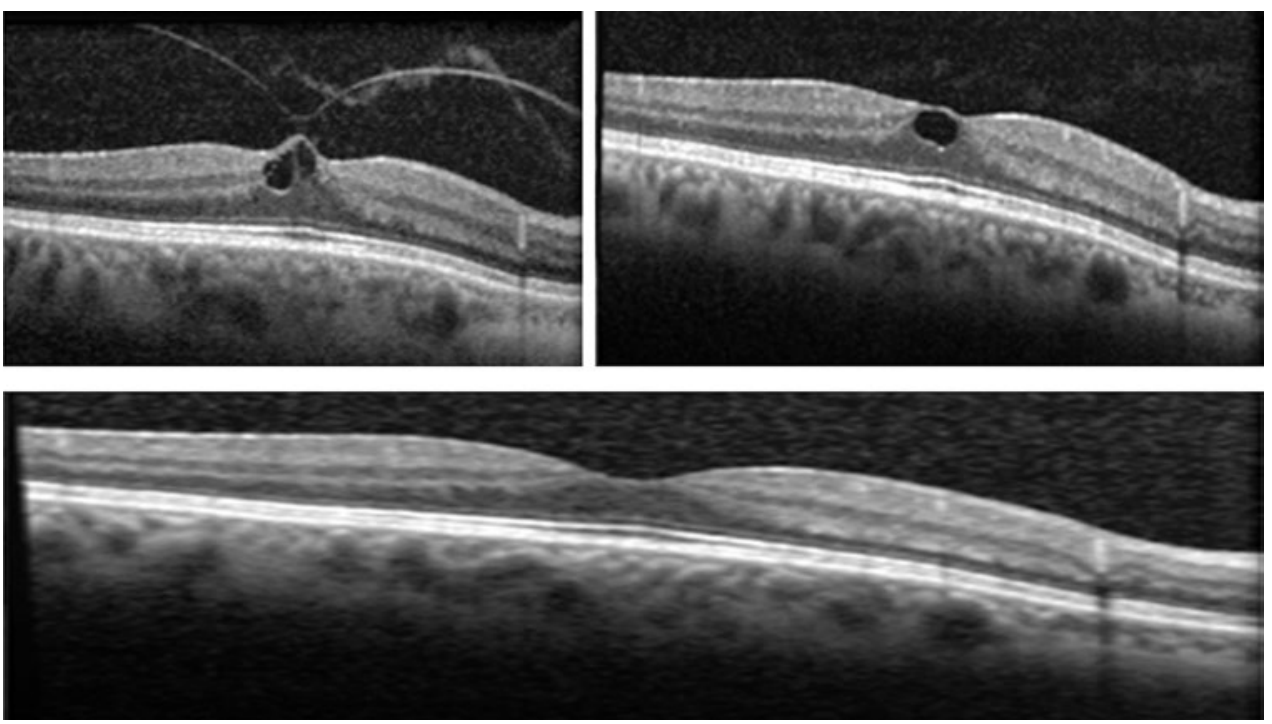

Figure 1. Right eye. VMT (upper left image). Spontaneous VMT resolution (bottom image).
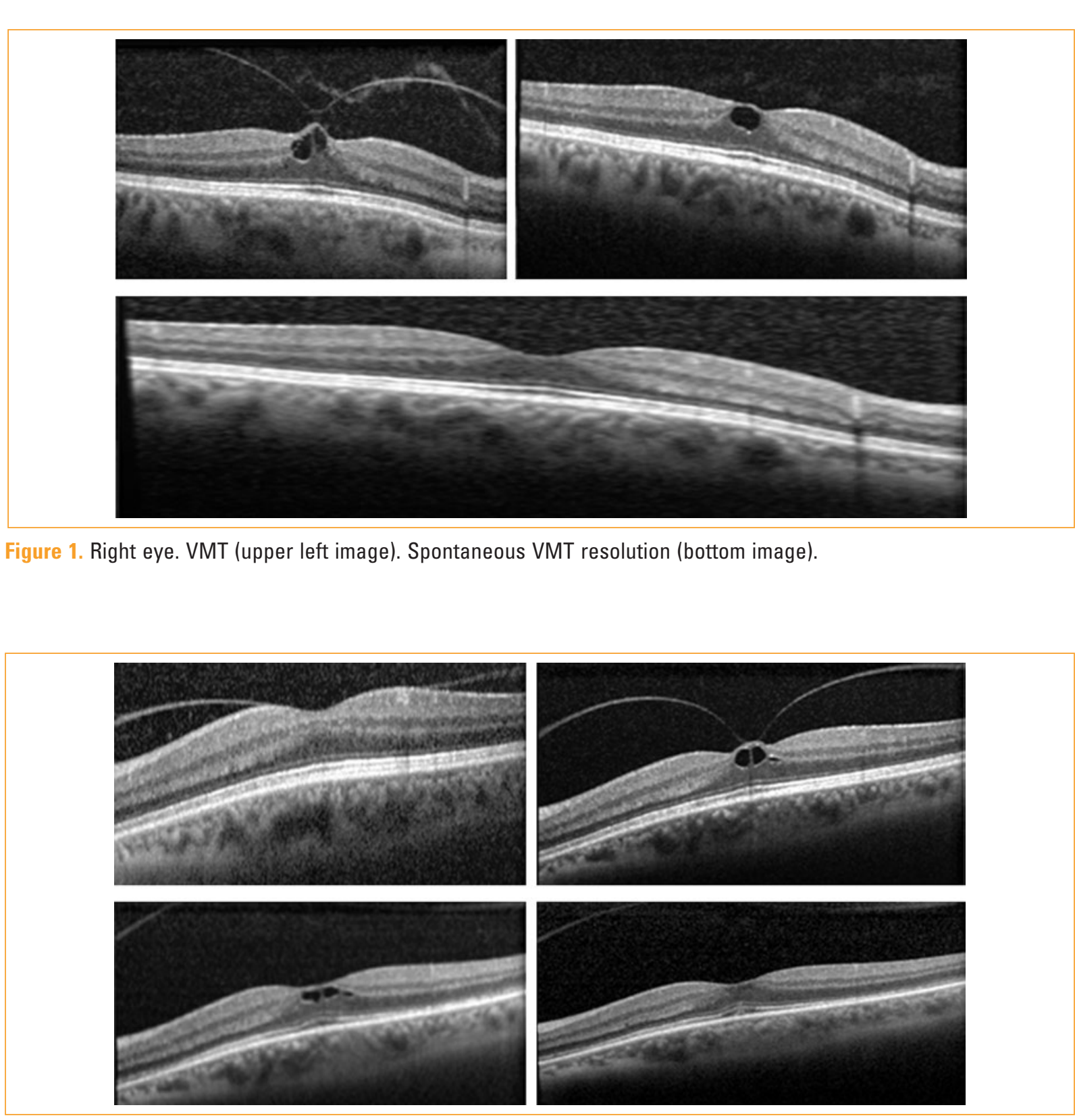

Figure 2. Left eye. Vitreomacular adhesion (upper left image). Vitreomacular traction with "gull wings" configuration plus intraretinal cysts (upper right image). Appearance of the foveal profile one week after ocriplasmin (bottom left image). Foveal profile preserved 12 months later (bottom right image).

Another treatment option would be vitreo-retinal surgery ${ }^{2}$. This implies the risk of complications such as infections, retinal detachment, hemorrhages and cataracts ${ }^{4}$.

Although surgery offers very good results in the treatment of this macular disease, we have already discussed its possible complications. In addition, treating a disease with a complex surgical procedure or with an intravitreal injection does not have the same repercussions, neither for the patient nor for the health system.
The results of two multicentric, phase 3 clinical trials have been recently published, which compared the results of a single injection of $125 \mathrm{yg}$ of ocriplasmin versus a placebo injection in patients with symptomatic $\mathrm{VMT}^{5}$. These results open new possibilities in the treatment of symptomatic VMT and macular hole. For the first time, a pharmacological treatment may obviate the need to perform a vitrectomy ${ }^{3,5}$.

Pharmacological vitreolysis achieves the release of vitreomacular adhesion in a gentle manner. By using 
an enzyme, a recombinant protease, the molecular substrate responsible for vitreomacular adhesion is degraded. It acts against laminin and fibronectin, components of the vitreo-retinal interface ${ }^{4}$.

Normally, release is achieved in the first seven days after the intravitreal injection'.

Our patient presented all the good prognosis criteria for pharmacological vitreolysis: younger than 65 years old, absence of epiretinal membrane, adhesion diameter less than $1,500 \mathrm{ym}^{1}$, which improves the final prognosis.

Some studies warn about the possibility of adverse effects such as photopsia and transient reduction of visual acuity that could indicate transient toxicity of ocriplasmin at the level of the external retina and retinal pigment epithelium ${ }^{4}$.

\section{Conclusions}

As in any maculopathy, diagnosis and early treatment are fundamental to obtain good results that allow maximum preservation of visual function, which can be achieved by enzymatic vitreolysis.

\section{Ethical disclosures}

Protection of human and animal subjects. The authors declare that the procedures followed were in accordance with the regulations of the relevant clinical research ethics committee and with those of the Code of Ethics of the World Medical Association (Declaration of Helsinki).

Confidentiality of data. The authors declare that no patient data appear in this article.

Right to privacy and informed consent. The authors declare that no patient data appear in this article.

\section{Funding}

The author(s) received no specific funding for this work.

\section{Conflict of interest}

The authors declare no conflict of interest.

\section{References}

1. Bottos J, Elizalde J, Arevalo J. Vitreomacular traction syndrome. J Ophthalmic Vis Res. 2012;7:148凶61.

2. Manejo del agujero macular. Guías de práctica clínica de la Sociedad Española de Retina y Vítreo. Madrid: Sociedad Española Retina y Vítreo; 2011.

3. Steel D, Lotery A. Idiopatic vitreomacular traction and macularhole: A comprehensive review of pathophysiology, diagnosis, and treatment. Eye. 2013;27 Suppl 1:S1-21.

4. Arias L. Tratamiento no quirúrgico de la tracción vitreomacular y del agujero macular. Arch Soc Esp Oftalmol. 2013;88:455-7.

5. Singh R, Li A, Bedi R. Resultados anatómicos y visuales del tratamiento con ocriplasmina. J Ophtalmol. 2014:98:356-60. 